\title{
Repeated measures study of the association between musculoskeletal symptoms and mental health in subway workers
}

\author{
Yun-Sik CHO', Jae-Bum PARK ${ }^{1,2}$, Soojeong $\mathrm{KIM}^{3}$ and Kyungjong LEE ${ }^{1,2}$ * \\ ${ }^{1}$ Department of Occupational and Environmental Medicine, Ajou University Hospital, Korea \\ ${ }^{2}$ Department of Occupational and Environmental Medicine, Ajou University School of Medicine, Korea \\ ${ }^{3}$ Department of Health Administration, Dongseo University, Korea
}

Received October 10, 2018 and accepted March 20, 2019

Published online in J-STAGE March 30, 2019

\begin{abstract}
While the prevalence of musculoskeletal disorders has recently increased among Korean workers employed in highly physically and psychologically demanding jobs, the relation among these domains remains relatively unexplored. We examined 2,037 subway workers in Seoul, that collected data via questionnaire survey on musculoskeletal symptoms and the work environment, administered in 2009, 2012, and 2015. Generalized estimating equation (GEE) analysis was used for statistical analysis. After conducting GEE analysis by adjusting for the sociodemographic and occupational characteristics, we found the prevalence of musculoskeletal symptoms significantly increased in cases with high Depression, Anxiety and Stress Scales (DASS) scores compared with low DASS scores, especially on shift workers. An integrated management method that considers ergonomic and mental health factors, should be used to better manage musculoskeletal symptoms in subway workers.
\end{abstract}

Key words: Mental health, Musculoskeletal symptoms, Repeated measures study, Shift work, Subway workers

\section{Introduction}

Musculoskeletal disorders (MSDs) are injuries or disorders of the muscles, nerves, tendons, joints, cartilage, and spinal discs. Work-related musculoskeletal disorders (WMSDs) are common in jobs requiring manual handling, heavy lifting, and/or repetitive motions. At present, MSDs are recognized as disorders that commonly develop in workers engaged in various occupations worldwide; however, the term musculoskeletal disorder was relatively

*To whom correspondence should be addressed.

E-mail: leekj@aumc.ac.kr

(C)2019 National Institute of Occupational Safety and Health unknown in Korea until 1996 and was not even mentioned in its Occupational Safety and Health $\mathrm{Act}^{1}$.

According to the Korea Occupational Safety and Health Agency (KOSHA), a total of 1,009 patients had WMSDs in 2000 in Korea, accounting for $24.9 \%$ of the total workrelated diseases; however, in recent years, this value has increased and was reported to be 5,213 in 2015, accounting for $65.8 \%$ of total work-related diseases ${ }^{2}$. There are major reasons of underreporting occupational diseases in Korea. Workers requesting an industrial accident compensation need to go through complex procedures by themselves. Also, many times, minor cases are dealt differently when workers negotiate for indemnity with a company ${ }^{3)}$. Only $20 \%$ of employees diagnosed with occupational diseases can be found in national industrial accident statistics ${ }^{4}$. 
While the number of workers who report WMSDs are low because of underreporting, we believe the distributions of WMSDs compared with other occupational illnesses and injuries would be similar in Korea. In Europe, WMSDs account for nearly half of the total work-related diseases, and reportedly affects approximately 4 million workers ${ }^{5}$. Moreover, WMSDs are responsible for $49.9 \%$ of work absence cases for $>3 \mathrm{~d}$ among workers in Europe and $60 \%$ of permanent work incapacity ${ }^{6}$. Such an increase in WMSD among workers might results in greater economic losses. Based on the claims filed for the National Health Insurance in 2011 in Korea, the number of lost working days for every 100,000 workers due to WMSD was 153,267 d. This amounted to an economic loss of 13 million USD. When these numbers are scaled up to the total number of workers in Korea, there are an estimated 39,850,000 lost working days per year with a relative economic loss of 3.5 billion $\mathrm{USD}^{7 \text { ). }}$.

Many studies have assessed the factors associated with musculoskeletal symptoms. Most of the early studies focused on physical exposure, such as manual material handling, repetitive movements, awkward postures, and vibration $^{8)}$, and subsequent studies explained the association between musculoskeletal symptoms and psychological risk factors, such as somatizing tendency, low mood, poor self-rated health, and psychosocial factors ${ }^{9-11)}$. The US National Institute of Occupational Safety and Health (NIOSH) defines job stress as "the harmful physical and emotional responses that occur when the requirements of the job do not match the capabilities, resources, or

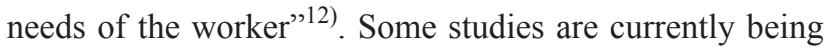
conducted not only stress itself, but also on the correlation between musculoskeletal symptoms and mental health parameters, such as anxiety and depression ${ }^{13,14)}$.

Although several studies have examined musculoskeletal symptoms, it is difficult to explain all the aspects of musculoskeletal symptoms in the workplace based on the individual risk factors identified. Socio-economic factors, such as healthcare availability, social security, and occupational safety and health need to be considered ${ }^{15}$.

Following an increase in the prevalence of musculoskeletal symptoms, Korea added the phrase "health problems caused by simple and repetitive work or work which requires excessive physical labor" to the Occupational Safety and Health Act in 2002; with this effort, Korea instituted a legal basis to prevent musculoskeletal symptoms ${ }^{1}$. A risk factor survey is currently ongoing regarding the workplaces with risk of musculoskeletal disorders (11 workplaces that have been linked with WMSDs defined by an ordinance of the Ministry of Employment and Labor) on a regular basis at 3 yr intervals; the study involves a basic survey, symptom questionnaire survey, and ergonomic evaluation. Various ergonomic evaluation tools are available, including the NIOSH Lifting Equation, Ergonomic Risk Factor Checklist, Ovako Working-posture Analysis System, Quick Exposure Checklist (QEC), Rapid Entire Body Assessment (REBA), Rapid Upper Limb Assessment (RULA), and Strain Index ${ }^{16)}$. After the risk factor survey identifies certain problems, the data are then transferred for adoption in a preventive management program; however, it is difficult to determine the specific changes in the workplace following the assessment of ergonomic exposures using these checklists. Moreover, there is a lack of data analysis on whether care and feedback are properly provided to workers with musculoskeletal symptoms.

The subway is one of the workplaces with musculoskeletal risk, and the prevalence of musculoskeletal symptoms among subway workers, including operators and mechanics, is reportedly $70-95 \%$, depending on the body part involved ${ }^{17,18)}$. According to the NIOSH, the incidence rate of anxiety, stress, and neurotic disorder is reportedly very high in the transport and public sectors ${ }^{19)}$, and the job stress of the operating crew in charge of driving in underground conditions is higher than most other occupations $^{20)}$. In particular, the "person under the train (PUT)" experience, which can occur during a railway accident or suicide, leads to marked psychological and mental stress in subway operators, and subsequently has been linked with occupational mental disorders, such as "panic disorder" and "post-traumatic stress disorder (PTSD)"21, 22). Although job stress and psychological health level may affect the musculoskeletal symptoms of subway workers to some extent, most of these studies are cross-sectional ${ }^{17,}{ }^{18}$ ) and only a few longitudinal studies have assessed their association with the symptoms. Currently, the preventive management program for musculoskeletal disease is being carried out in many workplaces, including subway corporation, in Korea, but the management of job stress is recognized as an individual's own problem.

In the present study, our aim was to analyze the association between musculoskeletal symptoms and the mental health of subway workers in Seoul based on a prospective longitudinal study that began in 2009. After controlling for covariates in the work environment through ergonomic work analysis, this study examined the changes in the prevalence of the workers' musculoskeletal symptoms over time and analyzed the mental health factors associated with the musculoskeletal symptoms. 


\section{Methods}

\section{Subjects}

This study was based on the musculoskeletal risk factor survey conducted in 2009, 2012, and 2015 on all the employees of a subway corporation that operates 4 of the 9 subway lines in Seoul. In 2015, a total of 6,524 employees worked at the corporation, which accounts for approximately $40 \%$ of all subway employees in Seoul. A university hospital in Korea had started the musculoskeletal risk factor survey in 2009 and conducted a preliminary survey, questionnaire survey, and worksite survey at 3 year intervals. The present study protocol was reviewed and approved by the Institutional Review Board of the Ajou University Medical Center in Suwon, Korea. AJIRBSBR-SUR-15-289, Location No. 1-No. 4 (22404, 22405, 22406, 22559). All participants signed a written informed consent.

\section{Data collection}

In this study, we used the musculoskeletal symptom questionnaire, recommended by the KOSHA, to identify musculoskeletal symptoms, and the Depression, Anxiety and Stress Scales (DASS) to assess mental health ${ }^{16,23}$. Work analysis was performed on 11 work activities known and considered to be related to musculoskeletal symptom risk interviews in which workers identified their working conditions and ergonomic evaluations using video-tape and analysis were also conducted.

\section{Measurement tools}

1) General characteristics

The general characteristics of the subjects consist of sex, age, accident history, and work shift.

\section{2) Ergonomic evaluation}

The QEC was used as an ergonomic evaluation tool and was designed by the Robens Centre for Health Ergonomics for the practical analysis of the risk factors of musculoskeletal disorders related to work ${ }^{24)}$. The evaluation items in the QEC included back, shoulder/arm, hand/ wrist, and neck, and the QEC was mainly used to assess the ergonomic risk of upper extremity disorders. The exposure percentage was calculated based on the QEC exposure scores. The required action was divided into 4 levels depending on the exposure percentage: "acceptable", $<40 \%$; "investigate further", 40-50\%; "investigate further and change soon", 50-70\%; and "investigate and change immediately", $\geq 70 \%{ }^{25)}$. We calculated the aver- age QEC score of the subjects for each work activity and assigned those with values $<40 \%$ to the "ergonomic risk: low group" and those with values $\geq 40 \%$ to the "ergonomic risk: high group". After excluding workers who were changed to different ergonomic groups over the 3 surveys (for example, in 2009: low risk group change to high risk group in 2012), a total of 2,037 subjects were finally included for analysis (Fig. 1).

\section{3) Musculoskeletal symptoms}

By using the musculoskeletal symptom questionnaire, based on the guidelines for surveys of work activities, on factors related to musculoskeletal risk established by the KOSHA, and on musculoskeletal symptom criteria defined by the NIOSH, we classified symptoms experienced by the subjects over the past year as neck, shoulder, arm/elbow, and hand/wrist/finger and examined the duration of pain, frequency, intensity, and treatment ${ }^{16,26)}$. In cases where a symptom was present on any part of the body, it was defined as 'any body part symptom' and was analyzed along with the neck symptoms and shoulder symptoms. Moreover, we used the criteria frequently used by NIOSH for the prevalence of subjective musculoskeletal symptoms and analyzed the presence or absence of these musculoskeletal symptoms; if "a symptom lasts for at least 1 week or occurs once or more per month in the past 1 year", it was considered to indicate musculoskeletal symptoms, and the other cases were considered not to have musculoskeletal symptoms ${ }^{27)}$.

\section{4) Mental health}

To identify the mental health level of the subjects, we used DASS data collected over $3 \mathrm{yr}$ - in 2009, 2012, and 2015 - and assessed depression, anxiety, and stress in the subjects. The DASS was developed by Lovibond ${ }^{23)}$, as a self-administered scale to assess negative emotional states, such as anxiety, depression, and stress. Each of the 3 DASS scales contains 14 items, divided into subscales of 2-5 items with similar content. The Depression scale assesses for dysphoria, hopelessness, devaluation of life, self-deprecation, lack of interest/involvement, anhedonia, and inertia. The Anxiety scale assesses for autonomic arousal, skeletal muscle effects, situational anxiety, and subjective experience of anxious affect. The Stress scale is sensitive to levels of chronic non-specific arousal and assesses for difficulty relaxing; nervous arousal; and being easily upset/agitated, irritable/over-reactive, and impatient. Subjects were asked to use 4-point severity/frequency scales to rate the extent to which they experienced each 


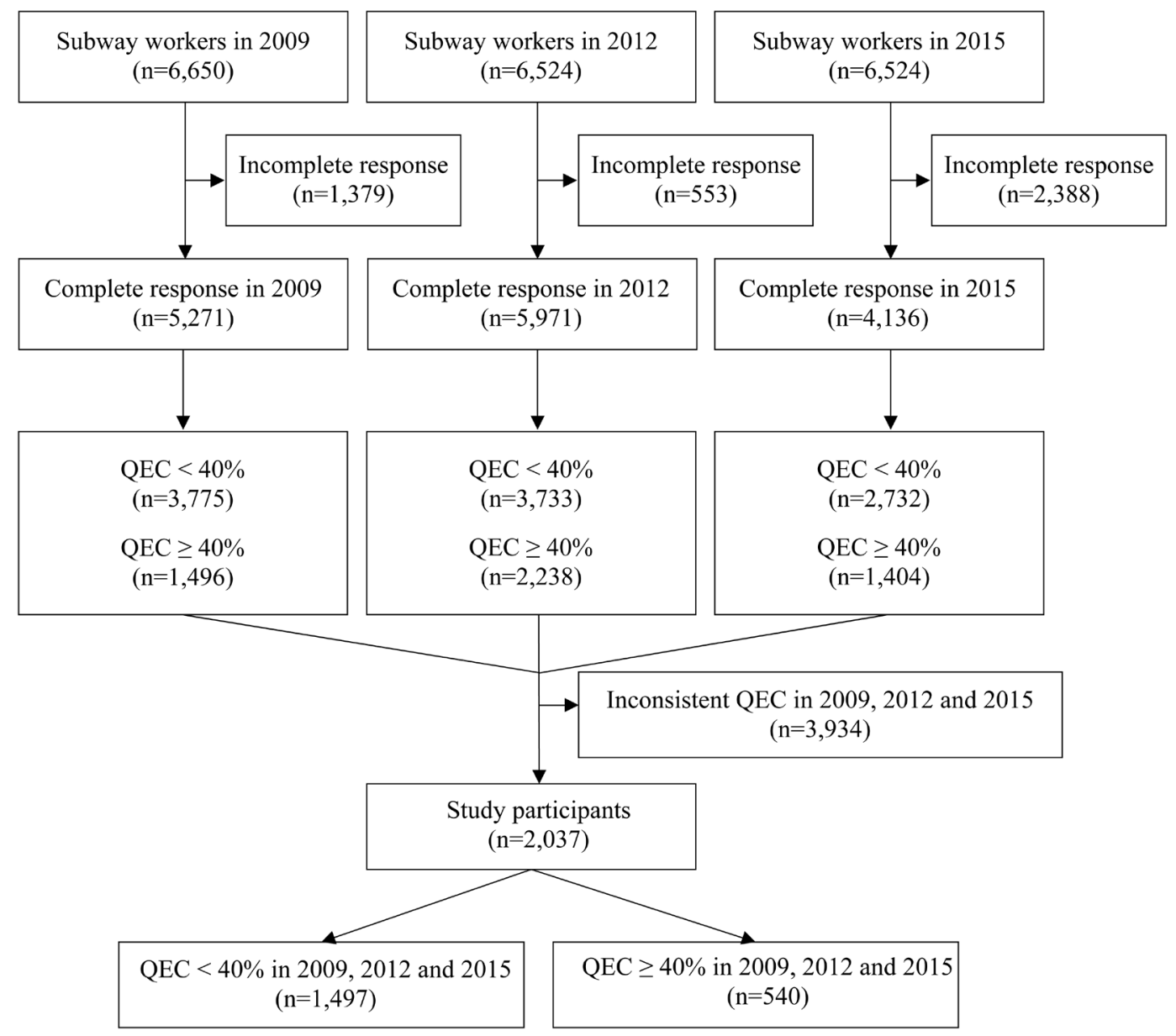

Fig. 1. Selection of study participants.

state over the past week. The DASS is then calculated as the sum of the scores of related questions, and based on these scales, the level of each item is classified as normal, mild, moderate, severe, and very severe ${ }^{23)}$. The DASS has shown high internal consistency and has produced significant findings in various studies ${ }^{28,29)}$. This study calculated the DASS scores, which were used to assign the subjects to the mild or lower (normal + mild) group and the moderate or higher (moderate + severe + very severe) group.

\section{Statistical analysis}

We conducted frequency analysis for the subjects' general characteristics and the presence of musculoskeletal symptoms in each year, and a chi-square test to compare the differences in the presence of musculoskeletal symptoms depending on the general characteristics. Moreover, to identify the association between musculoskeletal symptoms and the mental health level of the subjects, the study used a generalized estimating equation (GEE). The basic model of the GEE is similar to that of logistic regression analysis, but it derives the Exp (B) that considers $3 \mathrm{yr}$ of repeated measures. GEE is an analytical method that estimates the parameters of a generalized linear model with a possible unknown correlation between outcomes. GEE can be used to analyze longitudinal data sets which are comprised of repeated observations of an outcome variable and a set of covariates for each of many subjects ${ }^{30)}$. More importantly, since correlations exist between observations in medicine and health science studies where the binary response variables are measured several times, GEE should be preferentially applied in these cases ${ }^{31)}$. All statistical analyses were performed using SPSS (IBM Corp. Released 2014. IBM SPSS Statistics for Windows, Version 23.0. Armonk, NY: IBM Corp.), and all $p$ values $<0.05$ were considered to indicate statistical significance. 


\section{Results}

\section{General characteristics of the subjects}

A total of 5,271 of 6,650 (response rate, $79.3 \%$ ) employees in $2009,5,971$ of 6,524 (response rate, 91.5\%) employees in 2012, and 4,136 of 6,524 (response rate, 63.4\%) employees in 2015 participated in the musculoskeletal risk factor survey. We finally selected 2,037 employees for analysis as they were assigned to the same ergonomic group in the 2009, 2012, and 2015 surveys, and divided the subjects into 2 groups based on the QEC results. A total of 1,497 (73.5\%) were assigned to the low QEC group and $540(26.5 \%)$ were assigned to the high QEC group. The number of individuals who worked in shifts was $1,640(80.5 \%)$ in $2009,1,589(78.0 \%)$ in 2012 , and 1,583 in $2015(77.7 \%)$, thus indicating a gradual decrease over time (Table 1).

\section{Musculoskeletal symptoms}

Based on the musculoskeletal symptom questionnaire, we examined the prevalence of musculoskeletal symptoms in the subjects. The number of cases with neck symptoms was $84(4.1 \%)$ in 2009, $215(10.6 \%)$ in 2012, and 236 $(11.6 \%)$ in 2015 , which suggests that the prevalence of neck symptoms increased from 2009. Similarly, the number of those with shoulder symptoms gradually increased (Table 2).

\section{Mental health}

After measuring the subjects' scores for depression, anxiety, and stress through the DASS, we divided the subjects into 2 mental health groups. With regard to depression, the number of cases in the moderate-or-higher group was $211(10.4 \%)$ in 2009, which increased to 305 $(15.0 \%)$ in 2012 and slightly decreased to 298 (14.6\%)

Table 1. The sociodemographic characteristics of the study population

\begin{tabular}{|c|c|c|c|c|}
\hline & & 2009 & 2012 & 2015 \\
\hline \multicolumn{2}{|l|}{ Characteristics } & $\mathrm{N}(\%)$ & $\mathrm{N}(\%)$ & $\mathrm{N}(\%)$ \\
\hline \multirow[t]{2}{*}{ Sex } & Male & $1,976(97.0)$ & $1,976(97.0)$ & $1,976(97.0)$ \\
\hline & Female & $61(3.0)$ & $61(3.0)$ & $61(3.0)$ \\
\hline \multirow[t]{4}{*}{ Age (yr) } & $\leq 29$ & $69(3.4)$ & $3(0.1)$ & $0(0.0)$ \\
\hline & $30-39$ & $980(48.1)$ & $488(24.0)$ & $197(9.7)$ \\
\hline & $40-49$ & $830(40.7)$ & $1,278(62.7)$ & $1,470(72.2)$ \\
\hline & $\geq 50$ & $158(7.8)$ & $268(13.2)$ & $370(18.2)$ \\
\hline \multirow[t]{2}{*}{ Ergonomic risk } & Low (QEC < $<0 \%)$ & $1,497(73.5)$ & $1,497(73.5)$ & $1,497(73.5)$ \\
\hline & High (QEC $\geq 40 \%$ ) & $540(26.5)$ & $540(26.5)$ & $540(26.5)$ \\
\hline \multirow[t]{3}{*}{ Accident history } & No & $1,322(64.9)$ & $1,173(57.6)$ & $1,079(53.0)$ \\
\hline & Yes & $564(27.7)$ & $857(42.1)$ & $958(47.0)$ \\
\hline & Missing & $151(7.4)$ & $7(0.3)$ & $0(0.0)$ \\
\hline \multirow[t]{3}{*}{ Shift work } & No & $393(19.3)$ & $431(21.2)$ & $454(22.3)$ \\
\hline & Yes & $1,640(80.5)$ & $1,589(78.0)$ & $1,583(77.7)$ \\
\hline & Missing & $4(0.2)$ & $17(0.8)$ & $0(0.0)$ \\
\hline Total & & $2,037(100)$ & $2,037(100)$ & $2,037(100)$ \\
\hline
\end{tabular}

QEC: Quick Exposure Checklist.

Table 2. Musculoskeletal symptoms in the study population

\begin{tabular}{|c|c|c|c|c|}
\hline & & 2009 & 2012 & 2015 \\
\hline Body parts & Pain & $\mathrm{N}(\%)$ & $\mathrm{N}(\%)$ & N (\%) \\
\hline \multirow[t]{2}{*}{ Neck } & No & $1,953(95.9)$ & $1,822(89.4)$ & $1.801(88.4)$ \\
\hline & Yes & $84(4.1)$ & 215 (10.6) & $236(11.6)$ \\
\hline \multirow[t]{2}{*}{ Shoulder } & No & $1,823(89.5)$ & $1,767(86.7)$ & $1,750(85.9)$ \\
\hline & Yes & $214(10.5)$ & $270(13.3)$ & $287(14.1)$ \\
\hline \multirow[t]{2}{*}{ Any body part } & No & $1,610(79.0)$ & $1,433(70.3)$ & $1,439(70.6)$ \\
\hline & Yes & $427(21.0)$ & 604 (29.7) & $598(29.4)$ \\
\hline Total & & $2,037(100)$ & $2,037(100)$ & $2,037(100)$ \\
\hline
\end{tabular}


Table 3. Mental health groups, based on the DASS scores of the study population

\begin{tabular}{|c|c|c|c|c|}
\hline & & 2009 & 2012 & 2015 \\
\hline \multicolumn{2}{|c|}{ Mental health } & N (\%) & N (\%) & N (\%) \\
\hline \multirow[t]{2}{*}{ Depression } & Mild or lower & $1,826(89.6)$ & $1,732(85.0)$ & $1,739(85.4)$ \\
\hline & Moderate or higher & $211(10.4)$ & $305(15.0)$ & $298(14.6)$ \\
\hline \multirow[t]{2}{*}{ Anxiety } & Mild or lower & $1,706(83.8)$ & $1,692(83.1)$ & $1,679(82.4)$ \\
\hline & Moderate or higher & $331(16.2)$ & $345(16.9)$ & $358(17.6)$ \\
\hline \multirow[t]{2}{*}{ Stress } & Mid or lower & $1,953(95.9)$ & $1,924(94.5)$ & $1,913(93.9)$ \\
\hline & Moderate or higher & $84(4.1)$ & $113(5.5)$ & $124(6.1)$ \\
\hline \multicolumn{2}{|l|}{ Total } & $2,037(100)$ & $2,037(100)$ & $2,037(100)$ \\
\hline
\end{tabular}

DASS: Depression, Anxiety and Stress Scales.

in 2015. With regard to anxiety and stress, the number of cases in the moderate-or-higher group gradually increased (Table 3).

\section{Association between musculoskeletal symptoms and subjects' general characteristics}

A chi-squared test was used to analyze the differences in the presence of pain due to musculoskeletal symptoms, based on the subjects' general characteristics. With regard to sex, the prevalence in women was significantly greater than in men in all the surveyed years, although there was substantially fewer females in the study (3.0\%). With regard to age groups, musculoskeletal symptoms were found to increase in frequency among young people, from 2009 to 2015. With regard to the ergonomic risk groups, the high risk group showed a higher prevalence of musculoskeletal symptoms than the low risk group in all of the surveyed years. With regard to accident history, the group that had an accident showed a significantly higher prevalence of musculoskeletal symptoms in all the surveyed years. Overall, the individuals who did not work in shifts were more likely to answer that they had musculoskeletal symptoms as compared to those who did work in shifts (Appendix 1). Also, the results of the chi-square test for QEC groups and other variables were presented. The VIF value of all variables was $1.008-1.422$, which did not have multicollinearity problem (Appendix 2).

\section{Association between musculoskeletal symptoms and mental health}

To identify the association between mental health and the prevalence of musculoskeletal symptoms in the subjects, we used GEE analysis to calculate the odds ratio and a $95 \%$ confidence intervals (CI), while adjusting for the following variables: sex, age, ergonomic risk, accident history, and shift work. We found that, compared to the mild-or-lower group, the group with a moderate or higher level of depression showed a significant increase in neck symptoms by 2.08 times ( $95 \%$ CI, 1.66-2.61), shoulder symptoms by 1.99 times (95\% CI, 1.61-2.45), and any body part symptoms by 2.35 times (95\% CI, 2.00-2.77). Similarly, compared to the mild-or-lower group, the group with a moderate or higher level of anxiety showed a significant increase in neck symptoms by 1.93 times $(95 \%$ CI, 1.55-2.40), shoulder symptoms by 2.06 times $(95 \%$ CI, 1.70-2.50), and any body part symptoms by 2.18 times (95\% CI, 1.85-2.55). With regard to stress, compared to the mild-or-lower group, the moderate-or-higher group showed an increase in neck symptoms by 2.34 times $(95 \%$ CI, 1.67-3.27), shoulder symptoms by 2.35 times $(95 \%$ CI, 1.75-3.14), and any body part symptoms by 3.00 times (95\% CI, 2.32-3.87); the odds ratio for stress was greater than that for depression or anxiety. In addition, when analyzing the subjects through GEE on whether they work on shifts or not, shift working group showed significant correlation between musculoskeletal symptoms and mental health compared to non-shift working group (Table 4).

\section{Discussion}

In the present study, GEE was used to assess the repeated measurements conducted over 6 yr: 2009, 2012, and 2015. We found the prevalence of musculoskeletal symptoms significantly increased in cases with high DASS scores compared with low DASS scores, especially on shift workers.

The prevalence of musculoskeletal symptoms overall markedly increased from 2009 to 2012 and slightly increased or remained similar from 2012 to 2015. In addition, from 2009 to $2012,11.2 \%$ of the participants continued to suffer from musculoskeletal symptoms, but from 2012 to 2015 , they reached $14.2 \%$, suggesting that 
Table 4. Odds ratios (OR) and $95 \%$ confidence intervals (CI) of the musculoskeletal symptoms based on the DASS through GEE analysis

\begin{tabular}{|c|c|c|c|c|c|c|c|}
\hline \multicolumn{8}{|c|}{ All workers } \\
\hline \multirow{2}{*}{\multicolumn{2}{|c|}{ Mental health }} & \multicolumn{2}{|c|}{ Neck symptoms } & \multicolumn{2}{|c|}{ Shoulder symptoms } & \multicolumn{2}{|c|}{ Any body part symptoms } \\
\hline & & OR $(95 \% \mathrm{CI})$ & $p$-value & OR $(95 \% \mathrm{CI})$ & $p$-value & OR $(95 \% \mathrm{CI})$ & $p$-value \\
\hline \multicolumn{2}{|c|}{ Depression } & $2.08(1.66-2.61)$ & $<0.001$ & $1.99(1.61-2.45)$ & $<0.001$ & $2.35(2.00-2.77)$ & $<0.001$ \\
\hline \multicolumn{2}{|c|}{ Anxiety } & $1.93(1.55-2.40)$ & $<0.001$ & $2.06(1.70-2.50)$ & $<0.001$ & $2.18(1.85-2.55)$ & $<0.001$ \\
\hline \multicolumn{2}{|l|}{ Stress } & $2.34(1.67-3.27)$ & $<0.001$ & $2.35(1.75-3.14)$ & $<0.001$ & $3.00(2.32-3.87)$ & $<0.001$ \\
\hline \multicolumn{8}{|c|}{ By shift work } \\
\hline \multirow{2}{*}{$\begin{array}{l}\text { Shift } \\
\text { work }\end{array}$} & \multirow{2}{*}{ Mental health } & \multicolumn{2}{|c|}{ Neck symptoms } & \multicolumn{2}{|c|}{ Shoulder symptoms } & \multicolumn{2}{|c|}{ Any body part symptoms } \\
\hline & & OR $(95 \% \mathrm{CI})$ & $p$-value & OR $(95 \% \mathrm{CI})$ & $p$-value & OR $(95 \% \mathrm{CI})$ & $p$-value \\
\hline \multirow[t]{3}{*}{ No } & Depression & $1.25(0.78-1.99)$ & 0.359 & $2.13(1.42-3.20)$ & $<0.001$ & $2.31(1.65-3.24)$ & $<0.001$ \\
\hline & Anxiety & $1.35(0.88-2.07)$ & 0.169 & $1.55(1.05-2.31)$ & $<0.001$ & $1.75(1.27-2.42)$ & $<0.001$ \\
\hline & Stress & $1.46(0.72-2.98)$ & 0.292 & $1.83(0.95-3.52)$ & 0.069 & $2.91(1.71-4.95)$ & $<0.001$ \\
\hline \multirow[t]{3}{*}{ Yes } & Depression & $2.45(1.91-3.16)$ & $<0.001$ & $2.07(1.64-2.61)$ & $<0.001$ & $2.52(2.09-3.05)$ & $<0.001$ \\
\hline & Anxiety & $2.20(1.72-2.82)$ & $<0.001$ & $2.32(1.87-2.89)$ & $<0.001$ & $2.46(2.06-2.94)$ & $<0.001$ \\
\hline & Stress & $2.64(1.83-3.80)$ & $<0.001$ & $2.67(1.94-3.68)$ & $<0.001$ & $3.23(2.41-4.33)$ & $<0.001$ \\
\hline
\end{tabular}

Adjusted for sex, age, Quick Exposure Checklist (QEC), accident and shift work.

DASS: Depression, Anxiety and Stress Scales; GEE: Generalized estimating equation.

musculoskeletal symptoms are becoming chronic. This is inconsistent with the findings of Kim et al., who found that the number of musculoskeletal patients decreased by $76.2 \%$ from 2004 to 2008 and that the total economic losses decreased by $85.1 \%$ in workplaces in Korea that ran the preventive management program for musculoskeletal disease $^{32}$. Of course, the effects would have been large at the beginning of the program's introduction, and it would be a little harsh to compare them directly to current study. However, increasing musculoskeletal symptoms in this study means that the current preventive management program is insufficient to manage WMSD risk factors for subway workers. There is a need to improve the program in a way that involves the management of more various job stressors. The development of customized programs by job type is also worth considering.

In order to examine the dichotomous exposure categories among ergonomic factors that can affect the subjects' musculoskeletal symptoms, this study used QEC to divide the subjects into 2 ergonomic risk groups. The results of a chi-square test showed that overall, the high risk group had a higher prevalence of neck, shoulder, and any body part symptoms over all of the surveyed years. Although it was not presented in the Tables, the Exp (B) in GEE analysis was significant, with values of 1.3-1.5 $(p<0.05)$ for each of the different musculoskeletal symptoms. The findings of this study were consistent with those of the existing study ${ }^{25}$, which stated that action should be taken if the QEC percentage score is $\geq 40 \%$, similar to that reported in other QEC-based research on other occupations ${ }^{33,34)}$. As demonstrated above, the ergonomic risks in subway workplaces could be subjectively quantified by ergonomic experts and predicted to some extent, by using the ergonomic evaluation tool. The adoption of appropriate action, based on the ergonomic evaluation results, might make it possible to prevent or manage musculoskeletal symptoms in workers.

To analyze the subject's mental health, the DASS scores were assessed, which estimates the level of depression, anxiety, and stress among the subjects. Based on the DASS scores the subjects were assigned to 2 groups each for depression, anxiety, and stress. Over the course of $6 \mathrm{yr}$, we found that mental health was associated with musculoskeletal symptoms by using GEE. In those 2 groups that we assigned for depression, anxiety, and stress, the "moderate or higher" group showed approximately 2-3 times higher odds ratio in each of the musculoskeletal symptoms than the "mild or lower" group. These results were consistent with those of studies on the association between musculoskeletal symptoms and mental health factors such as depression, anxiety, and stress ${ }^{9,18)}$.

One notable aspect is that these correlations are more prevalently in shift working group than non-shift working group. More detailed investigation is needed to analyze the prevalence of WMSD between them which covers variety of factors like work hours, physical demands, occupational exposure, compensation, commute time, work schedule and so on ${ }^{35,36)}$. However, this study did not have 
enough data related to that. As a result, we could not find correlation between age and prevalence of musculoskeletal symptoms, even though analysis showed that higher the age groups tended to work less in shifts. In addition, nonshift working group shows tendency of higher prevalence of musculoskeletal symptoms, and there is no significant difference between DASS scores of shift working group and non-shift working group. However, considering previous studies about shift work and mental and physical health problem ${ }^{37,38)}$ as well as our GEE analysis, mental health of shift workers may influence on WMSDs. This is an area that needs further research.

Consequently, a more detailed evaluation of the musculoskeletal symptoms as well as an analysis of mental health using ergonomic tools designed to be specific to parts of the subway workers' body may be required. Furthermore, to manage musculoskeletal symptoms, we need to consider not only the ergonomic factors in workplaces, but also the social factors in the workplaces and the individual mental health problems, especially on shift workers.

Recently, intervention programs have attempted to mitigate mental illnesses such as PTSD or stress among the operators who experienced $\mathrm{PUT}^{39)}$; however, their expected effect was not very significant. To our knowledge, no program is being developed that can be applied to subway worker. However, the findings of the present study emphasize the need for measures related to the mental health of subway workers. The mental health of all workers, as well as subway workers, should no longer be regarded as a personal issue, but as something to be managed at a corporate and social level. It's also time to discuss the introduction of a program for mental health management, just as the preventive management program for musculoskeletal disease is being implemented in many workplaces.

This study has several limitations. First, although the analysis of mental health and the prevalence of musculoskeletal symptoms in the subjects has significant results, it is unclear which direction is the cause and the outcome. However, because ergonomic intervention alone is difficult to improve WMSDs, we would like to say that consideration of mental health is important in regards to musculoskeletal surveys and management. Second, it is difficult to generalize the findings of this study, as the study only examined subway workers in Seoul. However, it would be useful to compare these findings with those from other workplaces with activities that have similar musculoskeletal risk. Third, there is a possibility of misclassification, as 4 levels divided based on the QEC scores were consolidated into 2 groups. And it may not reflect the differences in the work environment or ergonomic factors among individuals in detail. Additionally, because we used QEC, we could not analyze the lower extremity symptoms which are found frequently in subway workers. Fourth, the analysis of lower back symptoms was not satisfactory. Although, a significance between other musculoskeletal symptoms and mental health has been identified, it is regrettable that lower back pain, an important musculoskeletal symptom that is common to subway workers, has been excluded from the analysis. Finally, changes in mental health could have been observed temporarily or chronically due to physical disease; however, there were limitations in controlling such acute or chronic disease history. And various data on personal, occupational, and social factors were not sufficient.

The strengths of the study are: First, it is a repeated measures study on a large number of subway workers; only a few such studies have been conducted thus far. Second, by assessing the ergonomic factors related to the physical symptoms in subway workers using validated tools and questionnaires and by evaluating mental health factors such as depression, anxiety, and stress using the DASS, the present study has made it easier for future studies to compare these groups using the same tools. Third, by conducting the questionnaire survey and work analysis simultaneously during the same time period, we could appropriately control for individual or workplace factors related to musculoskeletal symptoms. Fourth, we could observe distinctive changes by analyzing the association between mental health and musculoskeletal symptoms in subway workers, based on the repeated measures data surveyed 3 times over 6 yr. The study of Zhang et al. on musculoskeletal disease compared the use of logistic regression and GEE in the analysis of binary result variables. The study found that although the corresponding risks of each method were similar, the statistical power of the GEE analysis was higher than that of logistic regression analy$\mathrm{sis}^{40)}$. Furthermore, by identifying an association between musculoskeletal symptoms and depression, anxiety, and stress, we were able to describe appropriate measures for musculoskeletal health management in subway workers. Finally, we questioned the effectiveness of the preventive management program for musculoskeletal disease currently conducted in the country. Although the program was shown to be effective in other workplaces, we believe that it should be re-evaluated in the near future and should particularly be tailored for subway workplaces. 


\section{Conclusion}

In the present study, we sought to identify the association between musculoskeletal symptoms and mental health via a musculoskeletal risk factor survey on subway workers in Korea over 6 yr, in 2009, 2012, and 2015. The number of cases at high risk of depression, anxiety, and stress gradually increased. As a significant association between mental health and musculoskeletal symptoms was confirmed in this study, we believe that it is necessary to introduce stress and mental health improvement programs tailored to each workplace.

\section{Funding}

The authors report that there was no funding source for the work that resulted in the article or the preparation of the article.

\section{Conflict of Interest}

The authors have no potential conflicts of interest to disclose.

\section{References}

1) Lee DK, Kim JH (2010) A study on the prevention system of musculoskeletal disorders in Korea and other countries. J Ergon Soc Korea 29, 423-33. [CrossRef]

2) Korea Occupational Safety and Health Agency Occurrence of industrial accidents in 2015. https://www.kosha.or.kr/ www/boardView.do?contentId=363787\&menuId=554\&boa rdType=A2. Accessed October 10, 2016.

3) Kang SK (2011) The status of occupational accidents and injuries and the implications. Korean J Occup Environ Med 23, 351-9. [CrossRef]

4) Kim JH, Park SG, Leem JH, Won JU, Han SH, Chung SY, Kim SH, Kim HC, Hong YC, Kim CW, Kim CH, Kim DH, Lee DH, Lee SJ, Kang YJ, Kwak WS, Rhie J (2010) Areabased occupational disease surveillance in incheon, Korea: results of an 11-year data survey. Korean J Occup Environ Med 22, 183-99. [CrossRef]

5) Gauthy R (2007) Musculoskeletal disorders-an illunderstood "pandemic". European trade union institute for research, education. Health and Safety, Brussels.

6) Bevan S, Quadrello T, McGee R, Mahdon M, Vavrovsky A, Barham L (2009) Fit for work? Musculoskeletal disorders in the European workforce. The Work Foundation, 612-7.

7) Won JW (2015) Social and economic costs of musculoskeletal disorders; early diagnosis, treatment and management plan. Fit for Work Korea Forum, 25-37.

8) Bernard B (1997) Musculoskeletal disorders and workplace factors: a critical review of epidemiologic evidence for work-related musculoskeletal disorders of the neck, upper extremity, and low back, 97-141, DHHS (NIOSH) Publication, Cincinnati.

9) Linton SJ (2000) A review of psychological risk factors in back and neck pain. Spine 25, 1148-56. [Medline] [CrossRef]

10) Palmer KT, Reading I, Linaker C, Calnan M, Coggon D (2008) Population-based cohort study of incident and persistent arm pain: role of mental health, self-rated health and health beliefs. Pain 136, 30-7. [Medline] [CrossRef]

11) Macfarlane GJ, Pallewatte N, Paudyal P, Blyth FM, Coggon D, Crombez G, Linton S, Leino-Arjas P, Silman AJ, Smeets RJ, van der Windt D (2009) Evaluation of work-related psychosocial factors and regional musculoskeletal pain: results from a EULAR Task Force. Ann Rheum Dis 68, 885-91. [Medline] [CrossRef]

12) Sauter S, Murphy L (1999) Stress... at work, 99-101, DHHS (NIOSH) Publication, Cincinnati.

13) Bair MJ, Wu J, Damush TM, Sutherland JM, Kroenke K (2008) Association of depression and anxiety alone and in combination with chronic musculoskeletal pain in primary care patients. Psychosom Med 70, 890-7. [Medline] [CrossRef]

14) Poleshuck EL, Bair MJ, Kroenke K, Damush TM, Tu W, Wu J, Krebs EE, Giles DE (2009) Psychosocial stress and anxiety in musculoskeletal pain patients with and without depression. Gen Hosp Psychiatry 31, 116-22. [Medline] [CrossRef]

15) Farioli A, Mattioli S, Quaglieri A, Curti S, Violante FS, Coggon D (2014) Musculoskeletal pain in Europe: the role of personal, occupational, and social risk factors. Scand J Work Environ Health 40, 36-46. [Medline] [CrossRef]

16) Korea Occupational Safety and Health Agency. Guideline for researching harmful factors of musculoskeletal strain work. CODE H-9-2012. Accessed August 1, 2013.

17) Jung KH, Kim YC, Kang DM, Kim JW (2008) Study of the relation between work-related musculoskeletal disorders. Psychiatric disorders and job stress in train drivers. J Ergon Soc Korea 27, 1-7. [CrossRef]

18) Ganasegeran K, Perianayagam W, Nagaraj P, Al-Dubai SAR (2014) Psycho-behavioural risks of low back pain in railway workers. Occup Med (Lond) 64, 372-5. [Medline] [CrossRef]

19) Sestito JP, Lunsford RA, Hamilton AC, Rosa RR(2004) Worker health chartbook, 368-74, DHHS (NIOSH) Publication, Cincinnati.

20) Kang DM, Shin YC (2003) Research report: Working conditions, health status and the working environment assessment of urban railway workers. Korea Institute of Labor Safety and Health, Seoul.

21) Malt UF, Karlehagen S, Hoff H, Herrstromer U, Hildingson K, Tibell E, Leymann H (1993) The effect of major railway accidents on the psychological health of train drivers-I. Acute psychological responses to accident. J Psychosom 
Res 37, 793-805. [Medline] [CrossRef]

22) Theorell T, Leymann H, Jodko M, Konarski K, Norbeck HE (1994) 'Person under train' incidents from the subway driver's point of view - a prospective 1-year follow-up study: the design, and medical and psychiatric data. Soc Sci Med 38, 471-5. [Medline] [CrossRef]

23) Lovibond S, Lovibond P (1995) Manuals for the Depression Anxiety Stress Scales, 2nd ed. Psychology Foundation, Sydney.

24) David G, Woods V, Li G, Buckle P (2008) The development of the Quick Exposure Check (QEC) for assessing exposure to risk factors for work-related musculoskeletal disorders. Appl Ergon 39, 57-69. [Medline] [CrossRef]

25) Brown R, Li G (2003) The development of action levels for the "Quick Exposure Check" (QEC) system. Contemp Ergonomics 1, 41-6.

26) Cohen AL (1997) Elements of ergonomics programs: a primer based on workplace evaluations of musculoskeletal disorders, 97-117, DHHS (NIOSH) Publication, Cincinnati.

27) Bernard B, Sauter S, Fine L, Petersen M, Hales T (1994) Job task and psychosocial risk factors for work-related musculoskeletal disorders among newspaper employees. Scand J Work Environ Health 20, 417-26. [Medline] [CrossRef]

28) Crawford JR, Henry JD (2003) The Depression Anxiety Stress Scales (DASS): normative data and latent structure in a large non-clinical sample. Br J Clin Psychol 42, 111-31. [Medline] [CrossRef]

29) Nieuwenhuijsen K, de Boer AG, Verbeek JH, Blonk RW, van Dijk FJ (2003) The Depression Anxiety Stress Scales (DASS): detecting anxiety disorder and depression in employees absent from work because of mental health problems. Occup Environ Med 60 Suppl 1, i77-82. [Medline] [CrossRef]

30) Liang KY, Zeger SL (1986) Longitudinal data analysis using generalized linear models. Biometrika 73, 13-22. [CrossRef]

31) Lim HJ, Kim Y, Jung YB, Seong SC, Ahn JH, Roh KJ, Kim JM, Park BJ (2004) Analysis of repeated measured VAS in a clinical trial for evaluating a new NSAID with GEE method. J Prev Med Public Health 37, 381-9. [Medline]

32) Kim DS, Kim KS, Park JK (2009) A study for the efficient implementation management through the evaluating effectiveness of a WMSDs prevention program. Occupational Safety and Health Research Institute, Incheon.

33) Truszczyńska A, Scherer A, Drzał-Grabiec J (2016) The occurrence of overload at work and musculoskeletal pain in young physiotherapists. Work 54, 609-16. [Medline] [CrossRef]

34) Park HS, Kim J, Roh HL, Namkoong S (2015) Analysis of the risk factors of musculoskeletal disease among dentists induced by work posture. J Phys Ther Sci 27, 3651-4. [Medline] [CrossRef]

35) Caruso CC, Hitchcock EM, Dick RB, Russo JM, Schmit JM (2004) Overtime and extended work shifts: recent findings on illnesses, injuries, and health behaviors, 143, DHHS (NIOSH) Publication, Cincinnati.

36) Knauth P, Hornberger S (2003) Preventive and compensatory measures for shift workers. Occup Med (Lond) 53, 109-16. [Medline] [CrossRef]

37) Kang MY, Kwon HJ, Choi KH, Kang CW, Kim H (2017) The relationship between shift work and mental health among electronics workers in South Korea: a crosssectional study. PLoS One 12, e0188019. [Medline] [CrossRef]

38) Suzuki K, Ohida T, Kaneita Y, Yokoyama E, Miyake T, Harano S, Yagi Y, Ibuka E, Kaneko A, Tsutsui T, Uchiyama M (2004) Mental health status, shift work, and occupational accidents among hospital nurses in Japan. J Occup Health 46, 448-54. [Medline] [CrossRef]

39) Choi SK, Lee KS, Lee SY, Yu JH, Hong A, Chae JH, Chang SJ (2010) The effectiveness of an intervention program for subway operators for symptoms of post-traumatic stress disorder after the persons had fallen under a train. Korean $\mathrm{J}$ Occup Environ Med 22, 29-36. [CrossRef]

40) Zhang Y, Glynn RJ, Felson DT (1996) Musculoskeletal disease research: should we analyze the joint or the person? J Rheumatol 23, 1130-4. [Medline] 
Appendix 1. Comparisons of the characteristics of the study subjects according to the musculoskeletal symptoms

\begin{tabular}{|c|c|c|c|c|c|c|c|c|c|c|}
\hline \multirow[t]{2}{*}{ Characteristics } & \multicolumn{4}{|c|}{$\begin{array}{c}\text { Neck symptoms } \\
\text { Yes, } \%\end{array}$} & \multicolumn{3}{|c|}{$\begin{array}{c}\text { Shoulder symptoms } \\
\text { Yes, \% }\end{array}$} & \multicolumn{3}{|c|}{$\begin{array}{c}\text { Any body symptoms } \\
\text { Yes, } \%\end{array}$} \\
\hline & Year & 2009 & 2012 & 2015 & 2009 & 2012 & 2015 & 2009 & 2012 & 2015 \\
\hline \multirow[t]{2}{*}{ Sex } & Male & $3.9^{*}$ & $10.1^{*}$ & $11.2^{*}$ & $9.8^{*}$ & $12.8^{*}$ & $13.6^{*}$ & $20.0^{*}$ & $29.1^{*}$ & $28.7^{*}$ \\
\hline & Female & $9.8^{*}$ & $24.6^{*}$ & $24.6^{*}$ & $32.8^{*}$ & $29.5^{*}$ & $31.1^{*}$ & $50.8^{*}$ & $48.9^{*}$ & $50.8^{*}$ \\
\hline \multirow[t]{4}{*}{ Age (yr) } & $\leq 29$ & 7.2 & 33.3 & - & 5.8 & 33.3 & - & 20.3 & 33.3 & - \\
\hline & $30-39$ & 4.7 & 11.9 & $14.2^{*}$ & 11.0 & 12.9 & 16.8 & 21.8 & 28.9 & 34.0 \\
\hline & $40-49$ & 2.9 & 10.6 & $12.2^{*}$ & 10.4 & 13.1 & 14.1 & 19.8 & 30.6 & 29.5 \\
\hline & $\geq 50$ & 5.7 & 7.8 & $7.6^{*}$ & 10.1 & 14.2 & 12.4 & 22.2 & 26.5 & 26.2 \\
\hline \multirow[t]{2}{*}{ Ergonomic risk } & Low & $3.4^{*}$ & $9.2^{*}$ & $10.8^{*}$ & $9.1^{*}$ & $11.6^{*}$ & 13.4 & $19.9^{*}$ & $27.6^{*}$ & 28.7 \\
\hline & High & $6.1^{*}$ & $14.4^{*}$ & $13.7^{*}$ & $14.4^{*}$ & $17.8^{*}$ & 16.1 & $23.9^{*}$ & $35.4^{*}$ & 31.3 \\
\hline \multirow[t]{2}{*}{ Accident history } & No & $2.9^{*}$ & $7.4^{*}$ & $7.8^{*}$ & $8.4^{*}$ & $8.8^{*}$ & $9.4^{*}$ & $15.0^{*}$ & $19.0^{*}$ & $18.4^{*}$ \\
\hline & Yes & $7.3^{*}$ & $14.8^{*}$ & $15.9^{*}$ & $16.7^{*}$ & $19.3^{*}$ & $19.4^{*}$ & $36.7^{*}$ & $44.1^{*}$ & $41.8^{*}$ \\
\hline \multirow[t]{2}{*}{ Shift work } & No & 5.1 & 11.4 & $16.5^{*}$ & 11.5 & $15.5^{*}$ & $17.2^{*}$ & 22.9 & 31.8 & $35.7^{*}$ \\
\hline & Yes & 3.9 & 10.4 & $10.2^{*}$ & 10.3 & $12.7^{*}$ & $13.2^{*}$ & 20.5 & 29.1 & $27.5^{*}$ \\
\hline
\end{tabular}

${ }^{*} p<0.05$.

Appendix 2. Comparisons of the characteristics of the study subjects according to the QEC

\begin{tabular}{|c|c|c|c|c|c|c|c|c|c|c|}
\hline \multirow[b]{3}{*}{ Characteristics } & \multirow{3}{*}{$\begin{array}{l}\text { Year } \\
\text { QEC }\end{array}$} & \multicolumn{2}{|c|}{2009} & \multirow{3}{*}{$p$-value } & \multicolumn{2}{|c|}{2012} & \multirow{3}{*}{$p$-value } & \multicolumn{2}{|c|}{2015} & \multirow{3}{*}{$p$-value } \\
\hline & & $<40 \%$ & $\geq 40 \%$ & & $<40 \%$ & $\geq 40 \%$ & & $<40 \%$ & $\geq 40 \%$ & \\
\hline & & $\%$ & $\%$ & & $\%$ & $\%$ & & $\%$ & $\%$ & \\
\hline \multirow[t]{2}{*}{ Sex } & Male & 73.9 & 26.1 & 0.018 & 73.9 & 26.1 & 0.018 & 73.9 & 26.1 & 0.018 \\
\hline & Female & 60.7 & 39.3 & & 60.7 & 39.3 & & 60.7 & 39.3 & \\
\hline \multirow[t]{4}{*}{ Age (yr) } & $\leq 29$ & 71.0 & 29.0 & 0.057 & 33.3 & 66.7 & 0.183 & - & - & 0.143 \\
\hline & $30-39$ & 75.5 & 24.5 & & 73.6 & 26.4 & & 69.8 & 30.2 & \\
\hline & $40-49$ & 71.7 & 28.3 & & 74.3 & 25.7 & & 74.7 & 25.3 & \\
\hline & $\geq 50$ & 65.8 & 34.2 & & 69.8 & 30.2 & & 70.6 & 29.4 & \\
\hline \multirow[t]{2}{*}{ Accident history } & No & 74.0 & 26.0 & 0.450 & 73.1 & 26.9 & 0.401 & 72.8 & 27.2 & 0.258 \\
\hline & Yes & 73.6 & 26.4 & & 73.7 & 26.3 & & 74.2 & 25.8 & \\
\hline \multirow[t]{2}{*}{ Shift work } & No & 81.1 & 18.9 & 0.419 & 70.2 & 29.8 & 0.011 & 70.3 & 29.7 & 0.045 \\
\hline & Yes & 79.5 & 20.5 & & 76.4 & 23.6 & & 74.4 & 25.6 & \\
\hline
\end{tabular}

